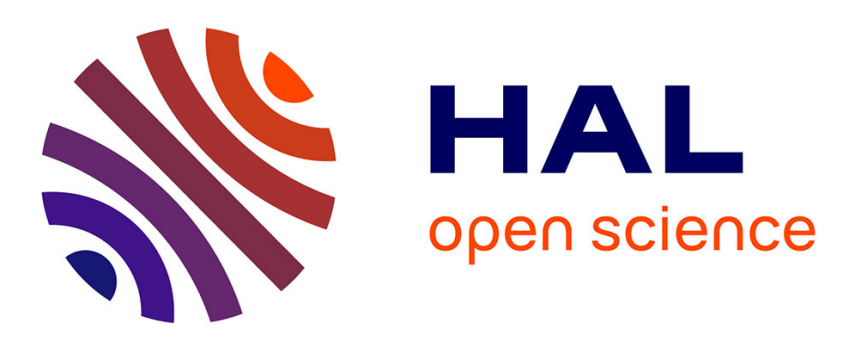

\title{
THERMOELASTIC GENERATION OF ULTRASONIC BY PULSE LASER
}

\author{
M.-A. Wei, S. L. Yang, M. Qian
}

\section{To cite this version:}

M.-A. Wei, S. L. Yang, M. Qian. THERMOELASTIC GENERATION OF ULTRASONIC BY PULSE LASER. Journal de Physique IV Proceedings, 1992, 02 (C1), pp.C1-797-C1-800. 10.1051/jp4:19921174 . jpa-00251135

\section{HAL Id: jpa-00251135 https://hal.science/jpa-00251135}

Submitted on 1 Jan 1992

HAL is a multi-disciplinary open access archive for the deposit and dissemination of scientific research documents, whether they are published or not. The documents may come from teaching and research institutions in France or abroad, or from public or private research centers.
L'archive ouverte pluridisciplinaire HAL, est destinée au dépôt et à la diffusion de documents scientifiques de niveau recherche, publiés ou non, émanant des établissements d'enseignement et de recherche français ou étrangers, des laboratoires publics ou privés. 


\title{
THERMOELASTIC GENERATION OF ULTRASONIC BY PULSE LASER
}

\author{
M.-A. WEI, S. YANG and M. QIAN \\ Institute of Acoustics, Tongii Univ., Shanghai, China (PRC)
}

\begin{abstract}
The hyperbolic thermal diffusion equation and Navier-Stokes equetion are used to find the temperature field and normal displacement field generated by a laser pulse in a semi-infinite medium. The theoretical results are presented. Using correlation method and spectrum analysis technique, the ultrasonic gruop and phase velocity in several samples are measured with laser-ultrasound technique.
\end{abstract}

L'équation hyperbolique de diffusion thermique et l'équation de Navier-Stokes sont utilisees pour trouver le champ de température et champ de deplacement normal produits par un inpulse de laser dans un medium semi-infini. Les resultats theoriques sont presentes. Utilisant la methode de correlation et la technique de 1'analyse spectrale, les vitesses ultrasoniques de groupe et de phase dans quleques échantillons sont mesurées avec la technique de laser-ultrason.

\section{Temperature Field}

When a $\delta(t)$ laser pulse is incident on a sample surface, a pulse heat source is formed and a rapid thermal expansion can be produced to generate detectable ultrasonic waves in the sample. The thermal power density of the heat source is given by

$g(\vec{r}, t)=\delta(r) \delta(z) \delta(t) / 2 \pi r$

Instead of the traditional parabolic thermal diffusion equation [1,2], the hyperbolic thermal diffusion equation is used to find the temperature distribution in a sime-infinite homogeneous and isotropic medium in order to avoid getting the impossible physical result that the thermal wave velocity would be larger than sound velocity in the medium when the laser pulse width is short enough. Then the temperature increment $T(\bar{r}, t)$ is determined by

$$
\left(1 / C_{T}^{2}\right)\left(\partial^{2} T / \partial t^{2}\right)+(1 / \alpha)(\partial T / \partial t)=\nabla^{2} T+g(\bar{r}, t) / k,
$$

and

$$
T(\vec{r}, 0)=\partial T(\vec{r}, 0) / \partial t=0,
$$

where $C_{T}$ is thermal wave velocity, $\alpha$ and $k$ are thermal diffutivity and conductivity of the medium, respectively.

Using Laplace-Henkel transform, the transform solution $\bar{T}^{*}(\mathrm{~s}, \mathrm{p}, \mathrm{z})$ is obtained from Eq.(2):

$$
\bar{T}^{*}(s, p, z)=\exp \left(-K_{t} z\right) / 4 \pi k K_{\imath},
$$

where

$$
K_{t}^{2}=\left(s / C_{r}\right)^{2}+(s / \alpha)+p^{2},
$$




$$
T(s)=\int_{0}^{\infty} T(t) \exp (-s t) d t, \quad T^{*}(p)=\int_{0}^{\infty} T(r) J_{0}(p r) r d r,
$$

Therefore the temperature field is obtained by inverse transform:

$$
T(r, z, t)=\left[H(t-z / C) \exp \left(-C_{T}^{2} t / 2 \alpha\right) / 4 \pi k\right] \int_{0}^{\infty} J_{0}\left[\left(p^{2} C_{T}^{2}-C_{T}^{4} / 4 \alpha\right)^{\frac{1}{2}}\left(t^{2}-z^{2} / C_{T}^{2}\right)^{\frac{1}{2}} J_{0}(p r) p d p\right.
$$

where $\mathrm{H}(\mathrm{t})$ is Heaviside step function.

\section{Normal displacement field}

The Navier-Stokes equetion for displacement $\vec{U}(\mathrm{Ur}, \mathrm{Uz})$ at point $\vec{r}(\mathrm{r}, \theta, \mathrm{z})$, when the temperature field is restricted on the sample surface, is

$$
\mu \nabla^{2} \vec{U}+(\lambda+\mu) V(\nabla \cdot \vec{U})-\rho \partial^{2} \vec{U} / t^{2}=0,
$$

where $\lambda$ and $\mu$ are Lame constants, and $\rho$ is density.

Introducing the scalar and vector potential $\varphi$ and $\vec{A}$, such that

$$
\bar{U}=\nabla \psi+\nabla x \bar{A}, \nabla \cdot \bar{A}=0
$$

Let $\mathrm{A}_{\theta}=-\partial \psi / \partial \mathrm{r}$, we get

$$
V^{2} \Phi-\left(1 / C_{1}^{2}\right) \partial^{2} \Phi / \partial t^{2}=0, \quad V^{2} \psi-\left(1 / C_{2}^{2}\right) \rho^{2} \psi / \partial t^{2}=0,
$$

and the initial conditions and boundary conditions are

$$
\begin{aligned}
& \Phi(r, z, 0)=\partial \Phi(r, z, 0) / \partial t=0, \psi(r, z, 0)=\partial \psi(r, z, 0) / \partial t=0, \\
& \tau z z(r, 0, t)=\lambda \nabla^{2} \Phi+2 \mu(\partial / \partial z)\left[\partial \Phi / \partial z+\partial^{2} \psi / \partial z^{2}-\left(1 / C_{2}^{2}\right) \partial^{2} \psi / \partial t^{2}\right]-(3 \lambda+2 \mu) \alpha T T=0, \\
& \tau r z(r, 0, t)=\mu(\partial / \partial r)\left[2 \partial \Phi / \partial z+2 \partial^{2} \psi / \partial z^{2}-\left(1 / C_{2}^{2}\right) \partial^{2} \psi / \partial t^{2}=0\right.
\end{aligned}
$$

where $C_{1}^{2}=(\lambda+2 \mu) / \rho, \quad C_{2}^{2}=\mu / \rho$, and $\alpha_{T}$ is thermal expantion coefficient.

Applying Laplace-Henkel transform to Eqs. (7)-(11), we obtain

$$
\begin{aligned}
\bar{U} z= & -[(3 \lambda+2 \mu) / 4 \pi k \mu] * \\
& \int_{0}^{\infty} \frac{k_{1}\left\{\left[\left(s / C_{2}\right)^{2}+2 p^{2}\right] \exp \left(-k_{1} z\right)-2 k_{1} p^{2} \exp \left(-k_{2} z\right)\right\} p J_{0}(p r) d p}{K_{t}\left\{\left[\left(s / C_{2}\right)^{2}+2 p^{2}\right]^{2}-4 k_{1} k_{2} p^{2}\right\}}
\end{aligned}
$$

where $k_{i}=p^{2}+\left(s / C_{i}\right)^{2}, i=1$ or 2 .

Using Cagniard method and $\mathrm{K}_{\mathrm{t}}^{2} \cong\left(\mathrm{s} / \mathrm{C}_{\mathrm{T}}\right)^{2}+\mathrm{p}^{2}$, the epicenter displacement $\mathrm{Uz}(\mathrm{r}=0)$ is obtained:

$$
\begin{aligned}
U z= & B^{\prime} * C_{2} \tau^{2}\left(2 \tau^{2}+\delta_{2}\right) H\left(t-z / C_{1}\right) /\left[\tau^{2}+\left(C_{2} / C_{\tau}\right)^{2}-\left(C_{2} / C_{1}\right)^{2}\right]^{\frac{1}{2}}\left\{\left(2 \tau^{2}+\delta_{2}\right)^{2}-4 \tau\left(\tau^{2}+\delta_{1}\right)^{\frac{1}{2}}\left[\tau^{2}\right.\right. \\
& \left.\left.-\left(C_{2} / C_{1}\right)^{2}\right]\right\} \\
& -B^{\prime} * 2 C_{2} \tau\left(\tau^{2}-1\right)\left(\tau^{2}-\delta_{1}\right) H\left(t-z / C_{2}\right) /\left[\tau^{2}+\left(C_{2} / C_{\tau}\right)^{2}-1\right]^{\frac{1}{2}}\left[\left(2 \tau^{2}-1\right)^{2}-4 \tau\left(\tau^{2}-1\right)\left(\tau^{2}-\delta_{1}\right)^{\frac{1}{2}}\right](1)
\end{aligned}
$$

where $\tau=C_{2} t / r, \delta_{1}=1-\left(C_{2} / C_{1}\right)^{2}, \delta_{2}=1-2\left(C_{2} / C_{1}\right)^{2}, B^{\prime}=B / Z$ and $B=-(3 \lambda$ $+2 \mu) / 4 \pi k \mu$.

The surface displacement $U z(z=0)$ can also be found by means of residual theorem. In the case of $\mathrm{C}_{\mathrm{T}}<\mathrm{C}_{2}<\mathrm{C}_{1}$, we get 
(a)
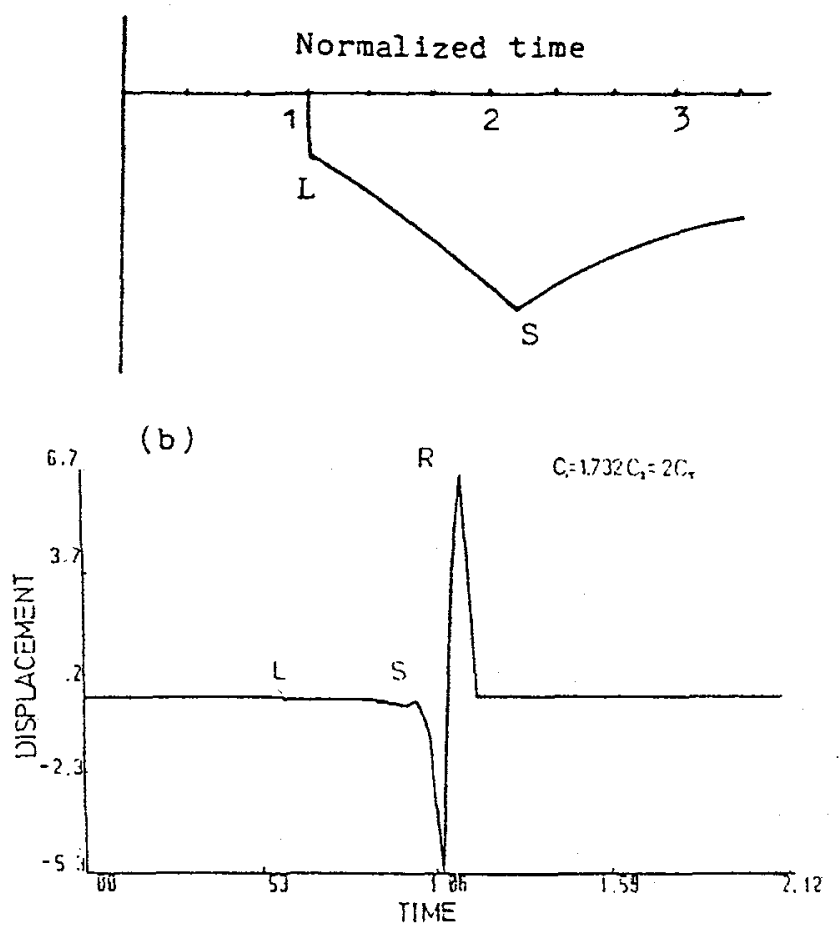

(c)

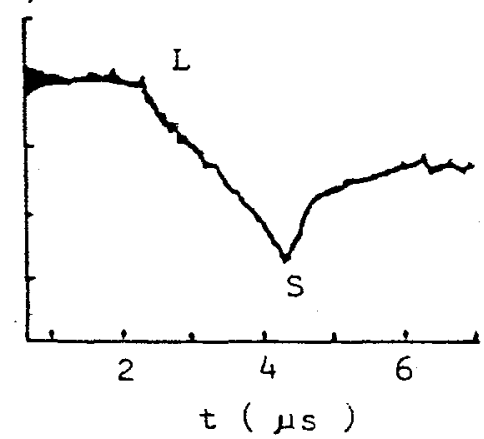

(d)

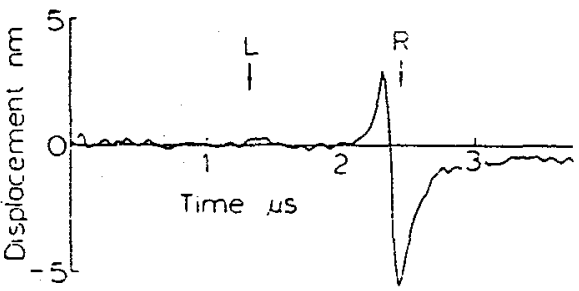

Fig.1-Normal displacement wave forms

(a) and (b) are theoretical results $U_{z}(r=0)$ and $U_{z}(z=0)$

(c) and (d) are experimental results $U_{Z}(r=0)$ of $A L$ and $U_{z}(z=0)$ of Steel measured by interferometer.

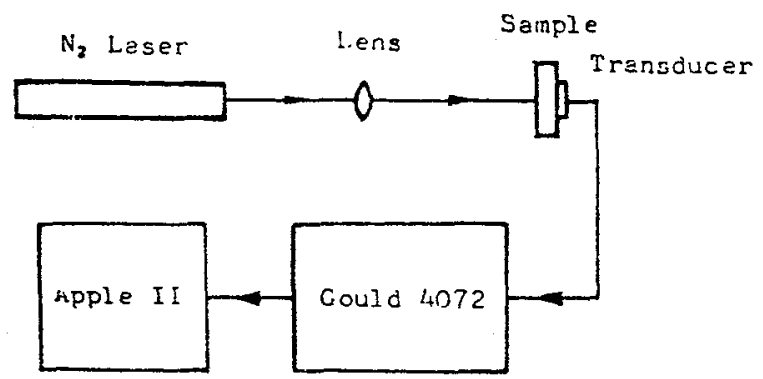

Fig.2- Laser-Ulitrasound system. 


$$
U_{x}=\left\{\begin{array}{rr}
0, & \left(0<\tau<C_{2} / C_{1}\right), \\
-\frac{2 B}{\pi r} \int_{0}^{\tau} \frac{C_{2} y\left(1-2 y^{2}\right)^{2}\left[y^{2}-\left(C_{2} / C_{1}\right)^{2}\right]^{\frac{1}{2}} d y}{\left[\left(C_{2} / C_{T}\right)^{2}-y^{2}\right]^{\frac{1}{2}}\left\{\left(1-2 y^{2}\right)^{4}+16 y^{4}\left(1-y^{2}\right)\left[y^{2}-\left(C_{2} / C_{1}\right)^{2}\right]\right\}\left(\tau^{2}-y^{2}\right)^{\frac{1}{2}}} & \left(C_{2} / C_{1}<\tau<1\right), \\
-\frac{2 B}{\pi r} \int_{0}^{\tau} & \frac{C_{2} y\left[y^{2}-\left(C_{2} / C_{1}\right)^{2}\right]^{\frac{1}{2}}\left\{\left(1-2 y^{2}\right)^{2}+4 y^{2}\left[y^{2}-\left(C_{2} / C_{1}\right)^{2}\right]^{\frac{1}{2}}\left(y^{2}-1\right)^{\frac{1}{2}}\right\} d y}{\left[\left(C_{2} / C_{T}\right)^{2}-y^{2}\right]^{\frac{1}{2}}\left\{\left(1-2 y^{2}\right)^{4}+16 y^{4}\left(1-y^{2}\right)\left[y^{2}-\left(C_{2} / C_{1}\right)^{2}\right]\right\}\left(\tau^{2}-y^{2}\right)^{\frac{1}{2}}} \\
& \left(1<\tau<C_{2} / C_{\tau}\right), \\
0, & \left(C_{2} / C_{T}<\tau\right) .
\end{array}\right.
$$

The normal displacement waveforms $U z(r=0)$ and $U z(z=0)$ are shown in Fig.1(a) and (b), respectively. They are in good agreement with the experimental results Fig.1(c)[3] and (d)[4].

3. Measurement of ultrasonic velocity

A laser-ultrasound experimental system is shown in Fig.2. The ultrasound pulse generated by a $\mathrm{N}_{2}$ pulse laser ( $337 \mathrm{~nm}, 8 \mathrm{~ns}$ and 6-8mJ ) and the train of echo pulses in the sample are detected by a PVDF film or PZT coupled with the sample. The ultrasonic pulses are recorded by a digital oscilliscope Gould 4072 and sent to a microcomputer to process. The correlation method and spectrum analysis technique are used to obtain the group and phase velocity of several samples. The experimental values of group velocity of $\mathrm{Al}$ and Steel are

$$
\mathrm{C}_{\mathrm{Ax}}=(6.438+0.029) \mathrm{km} / \mathrm{s}, \quad \mathrm{C}_{\text {Steel }}=(6.005+0.005) \mathrm{km} / \mathrm{s} \text {, }
$$

respectively. The phase velocity of $\mathrm{Al}$ and Steel are shown in Table 1. They are in good agreement with the theoretical values:

$$
\mathrm{C}_{\mathrm{AL}}=6417.74 \mathrm{~km} / \mathrm{s} \text { and } \mathrm{C}_{\text {Steel }}=5.941 \mathrm{~km} / \mathrm{s}
$$

Table 1 Experimental results of phase velocity

\begin{tabular}{|c|c|c|c|c|c|c|c|c|c|}
\hline Sample & $\mathrm{f}(\mathrm{MHz})$ & 20.5 & 22.1 & 24.4 & 25.9 & 26.6 & 30.7 & 32.3 & 33.9 \\
\hline $\mathrm{AL}$ & $\mathrm{C}(\mathrm{km} / \mathrm{s})$ & 6.40 & 6.41 & 6.41 & 6.40 & 6.41 & 6.40 & 6.39 & 6.40 \\
\hline & $\mathrm{f}(\mathrm{MHz})$ & 21.3 & 22.8 & 24.4 & 27.6 & 29.9 & 31.5 & 33.9 & 35.4 \\
\hline Steel & $\mathrm{C}(\mathrm{km} / \mathrm{s})$ & 5.96 & 5.95 & 5.96 & 5.97 & 5.95 & 5.95 & 5.96 & 5.96 \\
\hline
\end{tabular}

Therefore the laser-ultrasound method is a very powerful new technique for nondestructive testing.

* This work is Supported by Chinese Natural Science foundation.

\section{Reference}

1. Scruby,C.B., Dewhurst,R.J., Hutchich,D.A. \& Palmer,S.B., J.Appl.Phys., 51(1980)6210.

2. Rose,L.R.F., J.Acoust.Soc.Am., 75(1984)732.

3. Hutchins,D.A., Nadean,F. \& Cielo,P., 4th International Conference on Photoacoustic, Thermal and Related Sciences, 1985, Montreal,Canada.

4. Hutchins,D.A., " Physical Acoustics ", Vol.XVIII(1988),21-123, Ed. by P.Mason \& P.N.Thutston. Academic, New York. 